\title{
Propositions for Race-Based Research in Intellectual and Developmental Disabilities
}

\author{
Khalilah Robinson Johnson, Matthew Bogenschutz, and Kierra Peak
}

\begin{abstract}
A nuanced understanding of disparities impacting racialized people with intellectual and developmental disabilities (IDD) requires scholars employ research methods that make visible the structural factors that influence outcomes. Following the work of Tukufu Zuberi and Eduardo Bonilla-Silva, we explore race-based methodological considerations for disparities research with Black people with IDD. Specifically, we discuss (a) structural racism in research methods, employing disability critical race theory as a framework, (b) the absence of Black voices and Black scholarship, (c) the abstraction and misuse of race as a variable, and (d) mapping race as a point of discussion in the IDD discourse. Implications for research are discussed and recommendations for contextualizing race, ensuring equity in representation and dissemination, and amplifying the voices of Black scholars are provided.
\end{abstract}

Keywords: Black, developmental disability, DisCrit, intellectual disability, intersectionality, racism

Research in the field of intellectual and developmental disabilities (IDD) has contributed movement toward policy and practice that has built greater community inclusion for people with IDD. Transitioning from institutional care to community-based living, the advancement of inclusive educational practices, improving health outcomes, and slow progress toward community employment have all been documented and supported via research (e.g., Dean et al., 2015; Magaña et al., 2016; Siperstein et al., 2014). We should celebrate these advances (and others) and acknowledge that increasing inclusion for people with IDD would not have come about without the tireless efforts of researchers working alongside advocates, policymakers, practitioners, and support providers.

However, it is also important to acknowledge that the progress toward inclusion has not been equitably distributed for all people with IDD, and that researchers who work in the IDD field often have not done as well as possible to account for race and racism as factors that have slowed inclusion for Black people with IDD. In a majority White research space, researchers who study IDD have often been colorblind in how they have approached social issues facing people with IDD, and at other times have conflated the ideas of race and racism. Building on the work of sociological scholars Tukufu Zuberi and Eduardo Bonilla-Silva in their edited volume White Logic, White Methods (2008), this article aims to examine some of the ways in which pervasive Whiteness has permeated IDD research, and how the field may be able to do more to understand and improve the experiences of Black people with IDD.

\section{Current Uses and Contexts of Race in IDD Research}

Prominent domains in IDD scholarship where race, specifically Black and African American, are mentioned include preventive health, health care, and health disparities (e.g., Arana et al., 2019; Stancliffe \& Lakin, 2006), employment and vocational rehabilitation (e.g., Moore et al., 2002, 2009), mental health and behavior symptomatology (e.g., Horovitz et al., 2013; Kalb et al., 2016), special education (e.g., Skiba et al., 2008), criminal justice (e.g., Tsagaris et al., 2016), community living, and institutionalization (e.g., Harrington et al., 2009; 
Howard et al., 2002); and the disparities they experience across these domains have been described extensively. More specifically, people who identify as Black or African American and have IDD experience poorer health outcomes, endure social isolation, confront limited work options and access to employment training opportunities, and have an increased risk of poverty compared to their White counterparts (Balcazar et al., 2012; Magaña et al., 2016; Wehman et al., 2015). Researchers have identified race and ethnicity as consistent predictors of the aforementioned outcomes for people with IDD for some time; however, a considerable gap remains in the interrogation of the use of racial classifiers as predictors in IDD scholarship, and in differentiation between race as a social construct (defined by the tone of one's skin) and racism (as a social factor that creates disparities such as those noted above; Zuberi \& Bonilla-Silva, 2008).

Unpacking the nuances of disparities based on racial identity requires scholars who study IDD to employ research methods and analyses that reveal the structural and social influences impacting outcomes, as well as identify and examine power relations, oppression, and privilege; amplify the voices of those occupying multiple historically marginalized identities; and decenter the interests of White researchers and others with privileged status/positionality; because race, in and of itself, does not produce disparities and inequalities, racism and the structures that splinter from its systemic core do. Drawing on the work of Zuberi and Bonilla-Silva (2008), this article explores methodological considerations to better address disparities and outcomes for Black people with IDD. We discuss (a) structural racism in research methods and employing disability critical race theory as a theoretical guidepost, (b) the absence of Black voices and Black scholarship in the IDD field, (c) the abstraction and misuse of race as a variable, and (d) mapping race as a point of discussion in the IDD discourse. We aim to call in IDD scholars to actionable applied research that will move the field forward toward critical contextualization of race and racism, ensure equity in representation and dissemination, and amplify the voices of Black scholars and Black people with IDD in research.

Researchers have undercontextualized and underintellectualized race (LaVeist, 1994; Zuberi \& Bonilla-Silva, 2008). That is, the challenges facing racialized groups with IDD, namely Black people with IDD, that are identified and described by scholars are not informed by the contexts through which they emerge. Rice et al. (2019) refer to the performative inclusion of race in research as a rhetorical investment, "Employing additive approaches to consider the characteristics of two or more social markers without considering complexities which emerged at these junctures, and without acknowledgement of the broader social context in which identities and differences are considered and constructed" (p. 412). Therefore, it is necessary for IDD scholars to apply intersectional and race-centric frameworks to deepen their exploration of disparities and other social inequalities and inequities, rather than the cursory inclusion of race because it is "the thing to do." Analyzing and contextualizing the factors that mediate equity gaps allows researchers to see how they can muddy, enfold, and interact in various ways to reveal knowledge.

Contextualizing race and racism also foregrounds the intersections of the physical, social, temporal, economic, and cultural environments with its sociopolitical histories and socioaffective components, grounding knowledge and actions in understanding how different forms of power influence social relations and knowledge generation (Zuberi \& Bonilla-Silva, 2008). Researchers' treatment of context matters with regard to disclosing how the environment influences our understanding of disparities and the narratives that become normalized as a result; therefore, IDD scholars should aim to challenge these conceptualizations and offer appropriate alternatives that make visible the structures and powers that mediate disparate outcomes for Black people with IDD. As we will discuss in the propositions that follow, race has become conflated with racism, and the intersecting structural oppressions that affect Black people with IDD, have often been disregarded by researchers who study IDD.

\section{Intersectionality}

Intersectionality theory is a way of recognizing and dissecting complexities of the world, people, and human experience within social contexts (Collins \& Blige, 2016; Crenshaw, 1991). It is rooted in structuralism; however, intersectionality scholars also draw from poststructuralism to theorize entanglements of difference, power relations, and the ways through which individuals resist contradictory categorizations (Rice et al., 2019). More specifically, the core foci of 
intersectionality include (a) social inequality, (b) power, (c) relationality, (d) social context, (e) complexity, and (f) social justice (Collins \& Blige, 2016; Rice et al., 2019). These foci add additional layers of complexity to understanding the roots of social inequality. From the vantage point of intersectionality, inequalities are not caused by a single factor such as race; rather, social inequalities are the result of interactions and transactions among multiple factors in the context of social power dynamics.

In addition to being a navigational tool, intersectionality theory encourages researchers to untangle how oppression, privilege, and dimensions of power transact through all social groups (Rice et al., 2019), and move beyond seeing social inequalities or other disparities through a raceonly lens (Collins \& Blige, 2016). Critical social science scholars have embraced intersectionality as theory, as an enhancement to qualitative methods (e.g., ethnographic interviews, narrative methods) and discourse analysis, and as a social analysis (Rice et al., 2019). People's lives and identities are constructed by various factors in diverse and mutually influential ways-race, ethnicity, gender, age, disability, nationality, religion, sexuality, and so forth (Collins \& Blige, 2016; Crenshaw, 1991); and these intersectional positionalities are interlocking, creating and co-creating simultaneously through structures of power. Power can be analyzed at these intersections and across domains, which provides heuristics for researchers to further examine power relations (Crenshaw, 1991). Relationality emphasizes the interconnections between entities, all of which must be examined in context. When applied to people with IDD from minoritized backgrounds, arguments about outcomes must include the historical, intellectual, and political contexts as well as the intersections of racism, ableism, sexism, class, and so forth that shape outcomes and beliefs about this population.

Although its popularity as a framework is evident, scholars have counter-argued that intersectionality (a) emphasizes differences which can be divisive, (b) perpetuates identity politics, (c) thwarts coalition building, and (d) frames identities as singular entities that are static rather than fluid (Cho, 2013; Cho et al., 2013; Collins, 2015; Hutchinson, 2001). Nonetheless, intersectionality adds breadth and depth to our understanding of how theory and research are interconnected and applied, particularly when it comes to how researchers engage people from racial and ethnic backgrounds with IDD in research. It serves as a guidepost through which IDD scholars can disrupt orthodoxies (Artiles, 2013) and grapple with the social tensions that their work must contend by answering who is it for, what is its purpose(s), how is it operationalized, what are its main assumptions, what are the social factors coordinating what people with IDD can and cannot do, and so on.

\section{Race-Based Propositions for IDD Research}

In White Logic, White Methods, Zuberi and BonillaSilva (2008) present four key fundamental problems plaguing race-focused research in sociology. We follow suit by applying their propositions to redress racism and gatekeeping in the IDD field, by first historicizing research methods as a tool of White supremacy and knowledge gatekeeping by excluding Black scholars, then describing how these practices are taken up in the field and perpetuated through research and scholarship.

\section{Proposition 1-Structural Racism in the Historical Development of Research Methods}

Research is undeniably influenced by the mindset and worldview of those who conduct it. Zuberi and Bonilla-Silva (2008) described logic as the basis through which methodologies (e.g., surveys, ethnography, aptitude tests, comparative history) are used to generate and analyze empirical research and reinforce reasoning utilized and accepted by researchers in their understanding of society. White logic, then, generates Western ways of knowing by re-asserting White supremacy through these research processes. White supremacy ideologies are ingrained in the foundation of these methodologies, granting knowledge generated by elite Whites as perpetual truth and denouncing the understanding of non-Whites to subjectivity (Zuberi \& Bonilla-Silva, 2008). This leads to the othering of viewpoints that do not affirm White logic and promote the marginalization of racially oppressed people throughout the research process, and evidence to further support the claims of Anglo-Saxon superiority (Zuberi \& Bonilla-Silva, 2008). Prevailing research methodologies are imbued with racist ideologies and therefore are also taken up in IDD research. 
During the rise of Social Darwinism in the late lenged, most notably by Stephen Gould who nineteenth century, research embraced eugenic argued Morton's work was heavily influenced by ideologies (Dennis, 1995). Social sciences were his racial bias. Gould's claims that Morton's developing during this time leading to the methods of measurements created more room production of research that further imposed the for his bias to influence the results and justify idea that people of African descent were not equal racial hierarchy were challenged vehemently; to those of European descent (Zuberi et al., 2015). however, Morton's work continues to be utilized These research practices reflected the belief of race as as evidence to defend racism. Gould also stated a genetic trait that predetermined a collection of that "unconscious manipulation of data may be a social attributes and justified racially motivated scientific norm" as researchers we are all people violence against marginalized groups (Zuberi, rooted in our sociocultural contexts that result in 2001; Zuberi et al., 2015). Sir Francis Galton many different truths (Gould, 1978, p. 503).

(1883), cousin to Charles Darwin, coined the term

As researchers, we seek answers to questions engenics and described it as improving the stock of through the comprehensive execution of methodfuture generations. Galton asserted the idea that ologies, develop software to analyze and interpret intelligence was genetically inherited and in order data, and translate findings to impact policies and to create a fitter stock of Western society, practices for the betterment of humankind. Our intelligent, often wealthy Anglo-Saxons should positionality cannot be fully removed from procreate and those deemed unfit or defective, established research processes that have been people of color and people with disabilities, developed to reinforce a particular Western way should not (Dennis, 1995). These early construc- of understanding. Therefore, presenting race-based tions, based in eugenics, linked race and IDD in a findings as truth without appropriate contextualway that has still not been reckoned with in the ization is a disservice to marginalized groups and IDD field.

to IDD research, generally. Researchers assert that

Galton eventually created the basis for intel- the scientific approach, when properly designed ligence testing and intelligence quotient (IQ) to be and executed, protects results from being influthe tool to endorse that people of color were enced by researcher bias and shows how science feeble-minded (Dennis, 1995; Fletcher \& Hattie, has the ability to "escape the bounds and blinders 2011). Deemed as an objective way to assess of cultural contexts" (Lewis et al., 2011). But to intelligence, IQ testing is provided to detect make these assumptions of Colorblindness and deviants of White logic (Ilyes, 2020). Galton's "objectivity" ignores the historical legacy of White influence did not end there. A key figure in the supremacy that has shaped today's preferred modern statistical revolution, Galton's correlation methods of knowledge generation, and disregards was adopted "as a vehicle to employ classical the painful legacy of the White logic of eugenics statistical theory in understanding social differ- which shaped much of the White methods that ence" (Zuberi et al., 2015, p. 113). This led pervades IDD research to the present.

statisticians on the pathway of evaluating race as a genetic characteristic and not a social construct ly IDD, are undoubtedly tied to racism. Therethat considered the social and historical contexts fore, frameworks that connect both race and dis/ pertinent to statistical questions related to race. In ability are critical to redressing racism in IDD other words, the conceptualization of race in early research and scholarship. Employing critical and statistics set the tone for racist applications of intersectional theoretical frameworks and methresearch methods to assert White supremacy odologies (Crenshaw, 1991; Delgado \& Stefancic, which continue to the present. 2017; López \& Warren, 2015) can orient

In anthropological research, Samuel Morton researchers to issues of power, positionality, and measured the volume of cranium skeletal remains difference in the research processes (Rice et al., of deceased persons from different racial back- 2019). Disability Critical Race Theory (DisCrit), grounds. The measurements were intended to which integrates the constructions of race and determine the internal capacity of one's brain to disability to education attainment, provides an justify an intelligence hierarchy with Anglo-Saxon intersectional analysis of racism and ableism, how Whites being at the top and Africans being at the they are constructed and maintained through the bottom in his published study in 1839 (Mitchell, interactions, discourses, and institutions that 2018). Morton's research was eventually chal- limits access and equity for people of color with 
disabilities (Annamma et al., 2013). DisCrit does not conflate race but helps to lay bare the misappropriation and misrepresentations of race and disability (Ferri \& Conner, 2006)-to be Black does not make a person be intellectually or developmentally disabled and to have IDD does not make a person Black or from another racialized group membership.

Critical inquiry and critical praxis (Collins \& Blige, 2016) are necessary to challenge the status quo and move the field toward "social justice and transformation change" (e.g., research design, methods, analysis, dissemination, etc.); yet, researchers in established disciplines, much like many researchers who study IDD, may find it difficult to adopt critical and intersectional frameworks as analytic tools and as praxis because theoretical frameworks and methodologies of their disciplines are grounded in Euro-Western thought (Rice at al., 2019). The IDD field needs more than a cursory mentioning of race and dis/ability. Researchers who study IDD, when they actually report race, focus on racial differences in their data without consistently determining why those differences exist. As a body of scholars, researchers who study IDD must reconcile that race and dis/ ability are co-constructed and co-constitutive, and that the experiences underscore the plight of Black people in the United States. Failure to do so ignores the complexity of the lived experiences of people who identify as Black and have IDD.

Until race and ethnicity are routinely and appropriately positioned as social constructs, the IDD field will see little change with respect to structural racism in its research processes and scholarship. There must be explicit attention to contextual factors when designing protocols and analyzing data; intentional inclusion of partners from the communities of study (e.g., Black adults with IDD as research partners in a study about healthcare access and utilization); and interdisciplinary collaborators with expertise in working with racialized and minoritized groups. These recommendations are discussed in further detail in Propositions 2, 3, and 4.

\section{Proposition 2-The Absence of Black Scholars in the IDD Field}

IDD research and theory development, like most other fields of inquiry, has traditionally been dominated by White scholars, and continues to be so. Zuberi and Bonilla-Silva (2008), in their introductory remarks for White Logic, White Methods, point to the preponderance of White scholars in sociology as a contributing factor to the methodological and logical flaws that have pervaded much research in their field, because inherent biases of prominent researchers have codified and reinforced questionable constructions of race, misuse of race as a variable, and a preference for methodological approaches that have historically been used to assert White supremacy. Zuberi and Bonilla-Silva (2008) point to the development of Black scholars as one way of challenging the racially biased norms that are embedded in typical social science research.

Even a simple, cursory look at the authors who are published in widely read IDD journals, such as American Journal on Intellectual and Developmental Disabilities, Intellectual and Developmental Disabilities, and Inclusion, the three journals sponsored by the American Association on Intellectual and Developmental Disabilities, reveals a clear deficiency of literature produced by researchers who identify as Black. This is not to suggest there are no Black researchers who are submitting manuscripts for consideration to these publications, or that products of scholarship by Black researchers who study IDD are not evidenced elsewhere, but it does underscore a critical need for diverse voices and perspectives in the field, which can help us move toward more nuanced and grounded understandings of the experiences of people with IDD. Additionally, there is an observable absence of Black IDD scholars in positions of leadership within the field, which directly impacts which topics are considered for inclusion when establishing the discipline's research priorities and addressing racism as a prominent point of discussion in IDD discourse.

To most effectively address issues of equity among people with IDD, we must first turn our lens inward and consider how the predominantly White community of researchers can be more inclusive for emerging Black scholars. Mentorship and showing Black scholars a pathway into IDD research from early in their career development are key to developing a larger base of Black IDD scholars. Volumes have been written about mentorship of Black students and researchers in predominantly White fields of study (e.g., Griffin et al., 2010; McCoy et al., 2015). A comprehensive overview of this literature is outside the scope of this brief article, however, 
it is important to touch on a couple key points to begin a greater conversation.

First, building a pipeline of Black scholars in the IDD field will take a longitudinal approach, beginning when promising students are early in their undergraduate studies, as STEM fields have recognized for some time (Griffin et al., 2010; Haeger \& Fresquez, 2017). Creating paid undergraduate research assistantships and being intentional about encouraging Black students to engage in IDD research activities can help to introduce the idea of moving into a career in IDD research. For graduate students, especially those in fields traditionally associated with IDD research, such as special education, allied health professions, social work, and psychology, it is important to build closer one-on-one mentoring relationships with Black students who express interest in IDD research and to help those students take important roles on research and writing projects. Potential mentors should be proactive in reaching out to Black students because many students may not feel comfortable stepping into the White space of IDD research without feeling that they will be supported. Conversely, when Black students approach potential mentors about their interests in IDD research, White mentors must be intentional in creating supportive learning environments in which Black students can thrive, understanding that this must be managed while negotiating the Whiteness of the IDD research environment and the privileges it bestows or denies to individuals who occupy the research space. It is more than providing the "nuts and bolts." White mentors must commit themselves not only to developing Black scholars' skills and expertise but also the mentors' own learning about equity and inclusion in research training (McCoy et al., 2015).

Mentorship must continue for early career Black researchers. Because the IDD field has relatively few prominent Black researchers, it is incumbent on White researchers to put in the essential work to learn how to become strong mentors and allies. For many new researchers, and especially Black researchers in a White field such as IDD, it may be helpful to have a Black mentor from another discipline or even a different research setting to help with the navigation of identity politics in the research community, in addition to a topically relevant mentor. The collaborators for this article provide an example of how team mentorship can operate. Dr. Khalilah
Johnson who identifies as Black and female has Black female mentors who are prominent scholars in health psychology and public health but is also mentored in IDD by Dr. Matthew Bogenschutz, who identifies as White and male. As the only Black faculty member in the Division of Occupational Science and Occupational Therapy at the University of North Carolina at Chapel Hill (UNC-CH), Johnson serves as a mentor to Kierra Peak, a doctoral student at UNC-CH who identifies as Black, a responsibility that is undoubtedly conferred to Black faculty in many university departments (Moore \& Toliver, 2010).

Second, it is important to bear in mind that many of the professional disciplines that drive IDD research are traditionally female-driven, meaning that intersecting identities will be normative as more Black researchers enter the IDD field. Because our positionality influences how we work and how our work is perceived by others, it is important that we maintain an intersectional lens, rather than a singular focus on race alone. As noted in the previous section, intersections amplify the power dynamics that have kept Black researchers out of IDD research over the years, and acknowledging these power hierarchies, both historical and present, is crucial to addressing them (Grant, 2012).

Third, we recommend that journal editors and peer reviewers re-examine the nature of the research that is being published in prominent IDD journals for the implicit messages it may be sending about what constitutes "evidence" or "science" or "quality." All these notions are subjective and are often defined by people in power positions, typically held by White scholars. As noted in recent public discourse via Twitter, academic journals continue to affirm racist manuscripts as quality evidence whereas papers challenging the use of race are routinely overlooked (Grubbs, 2020). As outlined in Propositions 1 and 3, the construction of what we in the social sciences understand to be "good" research has often been used to further assert White supremacy and marginalize Black communities. Thus, it is of little surprise that many Black scholars are uncomfortable engaging in research that reinforces paradigms of research based, in part, in eugenics, a practice that could, for some, conjure historical trauma (Henderson et al., 2016). Further, funded research opportunities, especially those sponsored by federal agencies, are often reserved for emerging scholars who come from 
specific schools of inquiry, which further alienates rising Black researchers who study IDD (Ginther et al., 2011). There are many ways of "knowing," and the IDD research community may be well served by increasing acceptance and visibility of robustly and rigorously conducted research from a greater multitude of research paradigms, epistemological orientations, and theoretical bases. Doing so will not only invite new and diverse voices more inclusively into the community of researchers who study IDD but will expand the sometimesconstrained ways in which we have come to understand the experiences of people with IDD as researchers in the field.

\section{Proposition 3-The Misappropriation of Race as a Variable}

In social science research, there has long been a struggle between viewing race as a social construct, that is susceptible to changes with time and context, and the idea that race is an immutable and measurable variable that is stable over time (James, 2008). Although a multitude of social science researchers, including those in the IDD field, purport to see race as a socially constructed and dynamic phenomenon (James, 2008; Omi \& Winant, 2015), how we treat race as a variable in our research suggests that, in practice, researchers in the IDD field think about race as a biologically fixed part of personhood, despite genetic evidence to the contrary. It is ultimately researchers' tendency to use race as a fixed attribute, rather than a dynamic part of the human experience, born out of social stratification and political struggle, that leads many researchers who study IDD to misuse race as a variable (James, 2008).

Social scientists tend to use race as a classification variable to sort respondents in their studies into distinct categories (LaViest, 1994). Though an erroneous use of race, this practice comes from a long history of racial classification, much of which has been used to reinforce racial hierarchies based in White supremacy. Some of the earliest classifications of race imputed characteristics of ones' soul as being indicated by the tone of one's skin, suggesting that Black bodies were indicative of Black souls, which were cast as binary opposites to the purity of Whiteness (Jardan, 1974, as cited in James, 2008). As noted in Proposition 1, the use of racial classifiers in research continued as a means of "proving" White supremacy through the eugenics period, during which time race and intelligence became inextricably linked, and we can continue to see the simultaneous misuse of both types of variables in today's IDD research.

The misappropriation of race as a variable is derived from its unfounded biological construction. Few researchers would say that the tone of one's skin, in and of itself, is the cause of disparate social outcomes for people with IDD or any other group. In fact, it is not race as a phenotype that determines social outcomes, but the racist societal structures that support our commonly held perceptions of race. For instance, if we wish to consider racial health disparities for people with IDD in how often they access (for example) cancer screening, it is less than plausible to assume that skin tone is what causes differential outcomes. Rather, it is racialized social structures related to segregation, the structure of the American healthcare system, and the training of healthcare professionals that more likely portend poorer outcomes for Black people with IDD.

Further, just as disability classifiers are not fixed, but rather subject to change over time with updated definitions and social constructions of dis/ability, so, too, are racial classifiers. For illustrative purposes, consider the notion of the autism spectrum, which the IDD field currently holds to be a definitive diagnosis that describes millions of people throughout the world. The origins of the autism diagnosis in the 1940s were of a condition related to schizophrenia, and in the time since have evolved to be attributed to "refrigerator mothers" in the 1950s and 1960s (Kanner, 1949), as a distinct developmental condition, beginning with the DSM-III in 1980 (American Psychiatric Association, 1980), as a spectrum with distinct features in milder and more severe presentations beginning with the $D S M-I V$ in 1994 (American Psychiatric Association, 1994), and finally to the continuous spectrum that we know today, which began in 2013 with the publication of DSM-V (American Psychiatric Association, 2013). With the varying construction of autism throughout the years, it is difficult to see how we might consider autism from 1950 as being equivalent to autism of 2021 in any meaningful analysis.

Likewise, race has undergone myriad changes in its construction over the decades, making it equally difficult to consider as a variable to enable comparisons in outcomes across time or social context. Although a full examination of the 
construction of race is outside the scope of this article (refer to James, 2008 or Khalfani et al., 2008 for descriptive purposes), some clear evidence for the changing nature of racial classification comes from the U.S. census. Early census counts had only three racial categories: White, Black, or Indian. Over time, additional classifiers have been added, often to help justify policy goals that reinforced White supremacy, such as the inclusion of "Chinese" as a racial category just before implementation of the Chinese Exclusion Act. It was not until the 2000 census that respondents could choose as many racial signifiers as they identified with, with the inherent underlying assumption that race is dynamic, and may change from generation to generation.

Underlying biologically based notions of both race and disability classifiers is the assumption that these factors are, at least to some extent, deterministic of one's life outcomes. This assumption may be seen as being rooted in what those of us in the disability field know as the medical model: the assumption that the root of a life outcome lies within an individual, and thus to improve the potential for positive outcomes we must fix what is wrong about the individual (Haegele \& Hodge, 2016). To improve the employment outcomes for a person with IDD, for instance, based on the medical model we should train that individual with new behaviors that more closely conform to society's preferences. Much in the same way, we may assume that we can improve employment prospects for a person of color if they can function well in White spaces. In each instance, we are assuming that conformity with majoritarian society's preferences is the key to success, rather than working on creating a more inclusive shared community, as would be fostered through adoption of the social model. Although most researchers who study IDD have adopted, to some extent, the notion of the social model, even a cursory look at recent IDD literature suggests that our use of race as a variable often does not comport with our desire to move away from stigmatizing labels of the medical model.

\section{Proposition 4-Race and Racism as Points of Discussion in IDD Research}

As discussed in Proposition 3, race and ethnicity are often used as predictors of disparate outcomes in IDD research (e.g., service access and utilization in children and adults, vocational rehabilitation, transition and secondary education). Disparities are characterized as byproducts of racialized group membership. Race, then, is conceptualized as a causal variable and falsely maintains that Black people with IDD cannot exist outside of their "otherness." Their "otherness" becomes the focal point of analysis (Artiles, 2013); however, racism and not race variables, have causal effects (Artiles, 2013; Zuberi \& Bonilla-Silva, 2008). Further, researchers routinely control for level of ID, socioeconomics or household income, sex, education, employment status, and language as they are believed to correlate to race (LaVeist, 1994). These social markers also serve as proxies for making and remaking racial stratification (James, 2008; Zuberi \& Bonilla-Silva, 2008); and the perpetuation of these social inequities can result from research that relies on the statistical categories of race and dis/ability (Stewart, 2008).

Public health researchers and social scientists began studying the health effects of racism in the 1990 s, and today it is understood that victims of racism fare poorer across all domains than their White counterparts (Gee \& Ford, 2011; Williams \& Mohammed, 2013a, 2013b). Although this research has been instrumental in shifting conceptualizations of race in research from biologic and genetic differences, there remains inadequate attention to the complexity of racism as a fundamental cause of disparities, particularly in the IDD discourse.

Conceptualizations of race affect how we construe quantitative representations of race (Artiles, 2013; Garcia et al., 2018) and because many quantitative studies fail to position race within a social context, it reinforces the assumption that race is not relational. Interpretations are validated by an underlying theory. If the theoretical framework is rejected, the interpretations have no foundation. That is, findings related to race and IDD that are not explained through theories of racialization and dis/ability will be judged to be baseless. We will refer to employment outcomes for Black transition-aged youth and adults as an example. Often employment studies do not report a theoretical framework through which statistical data were interpreted; rather, scholars rely on regression models to determine relationality which results in broad sweeping narratives that being Black and having IDD in and of themselves are tied to poor outcomes. An intentional disaggregation of the data can expose the heterogeneity among Black youth and adults with IDD and the 
pathways to their employment. Framing these pathways through an intersectional, DisCrit, or QuantCrit (quantitative approaches couched in Critical Race Theory) lens lends a different narrative, one that examines the structural conditions that shape access to and completion of employment opportunities.

Disparities research is predominantly explored through quantitative methods with occasional passive mentions of the structural barriers that reinforce and reproduce disparate outcomes. Statistically, researchers treat race as an individual attribute, and any model that presents race as a causal factor is implicating an association between race and a predictor variable across all representatives of racialized groups. Commonly used techniques, variable analyses and comparative analysis, seek to identify the factors that explain the race effect and compare two or more groups (e.g., White and Black, White and Latinx) to identify factors responsible for group disparities in outcomes. Rather than finding ourselves in variable-based statistical logjam, Stewart (2008) and Zuberi and Bonilla-Silva (2008) offer that scholars shift their thinking to focus on how social relations produce and preserve observed racial inequalities.

People with multiple intersecting marginalized identities have lived experiences that are qualitatively different, and the experiences specific to Black adults with IDD are rarely discussed. In Proposition 2, we called attention to the unintentional ways racist practices are taken up by White researchers that result in the exclusion of Black scholars from the IDD field. We also add that these same practices influence the exclusion of Black voices as research partners in the IDD research enterprise. We specifically use "partner" instead of "participant" as a way to signify the importance of including people with IDD in decision making at every level of the research process and that the questions and issues most important to that community are reflected in the research design (Nicolaidis et al., 2019).

Researchers are making efforts to measure the impact of structural racism on health (e.g., Dougherty et al., 2020); at present, there remains a critical need to develop a formal basis for research that concentrates on racism rather than interpretations of racial effects and underscores the complicated and at times contradictory ways in which social location and interactions for racialized people with IDD are linked to structural circumstances. Kaufman and Cooper (2001) explained:

When a racial/ethnic contrast is estimated in standard designs and interpreted as an effect internal to study participants, inference is complicated because variables that are intrinsic are causally antecedent to nearly all measurable covariates. That is, a person's race/ethnicity is fixed prior to his/her measured social, physiologic, and psychological status; all of these measurable factors are downstream of the exposure in a racially stratified society. (p. 294)

Therefore, any covariate may be considered a causal broker of disparities that will bias estimates of total effect due to an inadequacy of standard statistical methods (Kaufman \& Cooper, 2001).

Researchers face numerous challenges when writing about race. Kaplan and Bennett (2003), in their assessment of race and ethnicity in biomedical publications, noted three primary threats to reporting racial differences in context and with rigor: (a) accounting for limitations and imprecision of race-based data, noting that any set of categories is an approximation and not a neat fixed descriptor; (b) differentiating between race as a risk factor versus risk marker and determining how race may contribute to those differences; and (c) averting perpetuating racial stigmatization through their scientific communications. They go on to offer seven strategies to combat these challenges:

1. Specify the reason why race is used as a variable.

2. Describe how racial categories were assigned or chosen by research participants.

3. Do not use race as a surrogate for genetic variation.

4. Explicitly extricate race as a risk factor versus a risk marker in the hypotheses and findings.

5. Racism and discrimination should be included as a relevant factor when interpreting racial differences.

6. Adjust for all conceptually relevant measures when drawing comparison between racialized groups.

7. Avoid using stigmatizing, unscientific, and racist terminology. 
Table 1

Challenges and Suggestions for Improving Integration of Race in Intellectual and Developmental Disabilities Research

Challenges
Intellectual and developmental disabilitions origins in re
(IDD) research has its oritions that reinforce White supr
traditiological
Race is often misused as a biologit.
construct.

IDD research often does not account for race or racism at all.

There are relatively few Black researchers and leaders in the IDD field.

Epistemological, theoretical, and methodological frameworks that are valued in IDD research are often bound by White logic.

\section{Suggestions}

Have critical conversations about the historically common roots of research on race and IDD.

Employ intersectionality theory and methodology to contextualize and examine power in IDD research.

Use Disability Critical Race Theory (DisCrit) to help interrogate how use of research methods can marginalize or emancipate.

Discuss how racism has shaped our conceptualization of race and dis/ability.

Limit use of race as a fixed classifier/predictor variable.

Focus on the social factors that more directly determine life outcomes for people with IDD.

Critically examine whether the use of race as a variable is valid when evaluating research.

Name which racialized groups are included in the research sample.

Include the structural factors that reproduce racism and contribute to racial disparities in IDD research studies.

Value research methodologies that call attention to the factors that Black people with IDD say influence their lives.

Consider building criteria for peer review processes that build accountability for addressing racialized structures.

Predominantly White IDD research teams should discuss and examine how Whiteness permeates their work, and how their research can be more inclusive to Black colleagues and research partners.

White IDD researchers can proactively reach out to promising Black students to bring them into research projects.

Prominent IDD researchers can gain skills for successfully mentoring Black early career professionals, with particular attention to intersectionality.

Peer review criteria for journals, grant review panels, tenure and promotion committees, and so forth can clearly and explicitly state that a diversity of theoretical and methodological traditions are valued and rewarded equally.

Train early career professionals in methodologies that center the experiences of racialized and minoritized people with IDD.

Prominently feature research that de-centers White logic at conferences, professional meetings, and in publications. 
Accordingly, we recommend researchers who study IDD employ the aforementioned strategies in their writing:

1. Name which racialized groups were included in the sample of study.

2. Explicitly state why and how race and other social markers were used as variables.

3. Describe the theoretical frameworks used to interpret race-based data and how researcher bias was mitigated.

4. Map structural racism as a mediator of disparate outcomes.

5. Confirm that the terms and categories used to describe racialized groups are affirmed by research partners.

\section{Implications for Inclusion}

This article points to four main areas of concern with how researchers who study IDD have traditionally addressed issues of race and racism, both historically and in the present. In order to promote inclusion for all people with IDD, our research methods, and our researchers themselves, must be reflective of the many different ways of generating knowledge, and must honestly look at racism, not race, as a factor that shapes the experiences of people with IDD. Table 1 outlines several explicit and actionable steps, derived from the propositions discussed previously, that researchers who study IDD may take to be more responsive and inclusive to the experiences of Black people with IDD and to create a research community that is more inclusive for Black researchers, especially those in early career stages. The recommendations are not exhaustive, and all researchers who study IDD will need to be introspective in determining how they can contribute to a more inclusive research community that uses methods and theoretical orientations that more fully include the diversity of people with IDD and researchers. The time is long overdue for the field to re-examine its approach to race, and we must all take accountability for moving ourselves toward greater inclusion, just as we have proclaimed for people with IDD for decades.

\section{References}

American Psychiatric Association. (1980). Diagnostic and statistical manual of mental disorders (3rd ed.). American Psychiatric Association Publishing.

American Psychiatric Association. (1994). Diagnostic and statistical manual of mental disorders (4th ed.). American Psychiatric Association Publishing.

American Psychiatric Association. (2013). Diagnostic and statistical manual of mental disorders (5th ed.). American Psychiatric Association Publishing. https://doi.org/10.1176/appi. books. 9780890425596

Annamma, S. A., Connor, D., \& Ferri, B. (2013). Dis/ability critical race studies (DisCrit): Theorizing at the intersections of race and dis/ability. Race Ethnicity and Education, 16(1), 1-31. https://doi.org/10.1080/13613324. 2012.730511

Arana, E., Carroll-Scott, A., Massey, P. M., Lee, N. L., Klassen, A. C., \& Yudell, M. (2019). Racial/ethnic disparities in mammogram frequency among women with intellectual disability. Intellectual and Developmental Disabilities, 57(3), 177-187. https://doi.org/ 10.1352/1934-9556-57.3.177

Artiles, A. J. (2013). Untangling the racialization of disabilities: An intersectionality critique across disability models. Du Bois Reviere: Social Science Research on Race, 10(2), 329-347. https://doi. org/10.1017/S1742058X13000271

Balcazar, F. E., Taylor-Ritzler, T., Dimpfl, S., Portillo-Peña, N., Guzman, A., Schiff, R., \& Murvay, M. (2012). Improving the transition outcomes of low-income minority youth disabilities. Exceptionality, 20(2), 114-132. https://doi.org/10.1080/09362835.2012. 670599

Cho, S. (2013). Post-intersectionality. Du Bois Revierw: Social Science Research on Race, 10(2), 385-404. https://doi.org/10.1017/S1742058 X13000362

Cho, S., Crenshaw, K. W., \& McCall, L. (2013). Toward a field of intersectionality studies: Theory, application, and praxis. Signs: Journal of Women in Culture and Society, 38(4), 785810. https://doi.org/10.1086/669608

Collins, P. H. (2015). Intersectionality's definitional dilemmas. Annual Review of Sociology, 41, 1-20. https://doi.org/10.1146/annurevsoc-073014-112142

Collins, P. H., \& Bilge, S. (2016). Intersectionality. Polity Press.

Crenshaw, K. (1991). Mapping the margins: Intersectionality, identity politics, and vio- 
lence against women of color. Stanford Law Reviere, 43(6), 1241-1299. https://doi.org/10. 2307/1229039

Dean, E., Dunn, W., \& Tomchek, S. (2015). Role of occupational therapy in promoting selfdetermination through consumer-directed supports. Occupational Therapy in Health Care, 29(1), 86-95. https://doi:10.3109/07380577. 2014.958887

Delgado, R., \& Stefancic, J. (2017). Critical race theory: An introduction (3rd ed.). NYU Press.

Dennis, R. M. (1995). Social darwinism, scientific racism, and the metaphysics of race. The Journal of Negro Education, 64(3), 243-252. https://doi.org/10.2307/2967206

Dougherty, G. B., Golden, S. H., Gross, A. L., Colantuoni, E., \& Dean, L. T. (2020). Measuring structural racism and its association with BMI. American Journal of Preventive Medicine, 59(4), 530-537. https://doi.org/10. 1016/j.amepre.2020.05.019

Ferri, B. A., \& Connor, D. J. (2006). Reading resistance: Discourses of exclusion in desegregation e inclusion debates (Vol. 1). Peter Lang.

Fletcher, R. B., \& Hattie, J. (2011). Intelligence and intelligence testing. Taylor \& Francis Group.

Galton, F. (1883). Inquiries into buman faculty and its development. Macmillan.

Garcia, N. M., López, N., \& Vélez, V. N. (2018). QuantCrit: Rectifying quantitative methods through critical race theory. Race Ethnicity and Education, 21(2), 149-157. https://doi.org/10. 1080/13613324.2017.1377675

Gee, G. C., \& Ford, C. L. (2011). Structural racism and health inequities: Old issues, new directions. Du Bois Revierw: Social Science Research on Race, 8(1), 115-132. https://doi.org/10.1017/ S1742058X11000130

Ginther, D. K., Schaffer, W. T., Schnell, J., Masimore, B., Liu, F., Haak, L. L., \& Kington, R. (2011). Race, ethnicity, and NIH research awards. Science, 333(6045), 1015-1019. https://doi.org/10.1126/science.1196783

Gould, S. J. (1978). Morton's ranking of races by cranial capacity: Unconscious manipulation of data may be a scientific norm. Science, 200(4341), 503-509. https://doi.org/10.1126/ science. 347573

Grant, C. (2012). Advancing our legacy: A black feminist perspective on the significance of mentoring for African American women in educational leadership. International Journal of

Qualitative Studies in Education, 25(1), 101-
117. https://doi.org/10.1080/09518398.2011. 647719

Griffin, K., Perez, D., Holmes, A., \& Mayo, C. (2010). Investing in the future: The importance of faculty mentoring in the development of students of color in STEM. New Directions for Institutional Research, 2010(148), 95-103. https://doi.org/10.1002/ir.365

Grubbs, V. [@thenephrologist]. (2020 December 1). Can we stop medical journal reviewers/editors who green light racist manuscripts for publication [Tweet]. Twitter. https://twitter.com/ thenephrologist/status/133390959006530 3552 ? $s=20$

Haegele, J., \& Hodge, S. (2016). Disability discourse: Overview and critiques of the medical and social models. Quest, 68(2), 193-206. https://doi.org/10.1080/00336297. 2016.1143849

Haeger, H., \& Fresquez, C. (2017). Mentoring for inclusion: The impact of mentoring on undergraduate researchers in the sciences. Life Sciences Education, 15(3), 1-9. https://doi.org/ 10.1187/cbe.16-01-0016

Harrington, C., Kang, T., \& Chang, J. (2009). Factors associated with living in developmental centers in California. Intellectual and Developmental Disabilities, 47(2), 108-124. https://doi.org/10.1352/1934-9556-47.2.108

Henderson, Z., Acquaye-Doyle, L. A., Waites, S., \& Howard, T. (2016). Putting principles into practice: Addressing historical trauma, mistrust, and apprehension in research methods courses. Journal of Social Work Education, 52(1), 69-78. https://doi.org/10.1080/10437797. 2016.1112631

Horovitz, M., Matson, J. L., Hattier, M. A., Tureck, K., \& Bamburg, J. W. (2013). Challenging behaviors in adults with intellectual disability: The effects of race and autism spectrum disorders. Journal of Mental Health Research in Intellectual Disabilities, 6(1), 1-13. https://doi.org/10.1080/19315864.2011. 605989

Howard, D. L., Sloane, P. D., Zimmerman, S., Eckert, J. K., Walsh, J. F., Buie, V. C., Taylor, P. J., \& Koch, G. G. (2002). Distribution of African Americans in residential care/assisted living and nursing homes: More evidence of racial disparity? American Journal of Public Health, 92(8), 1272-1277. https://doi.org/10. 2105/AJPH.92.8.1272 
Hutchinson, D. L. (2001). Identity crisis: "Intersectionality," "multidimensionality," and the development of an adequate theory of subordination. Michigan Journal of Race \& Law, 6(2), 285-318. https://repository.law.umich. edu/cgi/viewcontent.cgi? article $=1198 \&$ context $=$ mirl

Ilyes, E. (2020). Psychology's eugenic history and the invention of intellectual disability. Social and Personality Psychology Compass, 14(7), 111. https://doi.org/10.1111/spc3.12537

James, A. (2008). Making sense of race and racial classification. In T. Zuberi \& E. Bonilla-Silva (Eds.), White logic, white methods: Racism and methodology (pp. 32-44). Rowman \& Littlefield Publishers.

Kalb, L. G., Beasley, J., Klein, A., Hinton, J., \& Charlot, L. (2016). Psychiatric hospitalisation among individuals with intellectual disability referred to the START crisis intervention and prevention program. Journal of Intellectual Disability Research, 60(12), 1153-1164. https://doi.org/10.1111/jir.12330

Kanner, L. (1949). Problems of nosology and psychodynamics of early infantile autism. American Journal of Orthopsychiatry, 19(3), 416-426. https://doi.org/10.1111/j.19390025.1949.tb05441.x

Kaplan, J. B., \& Bennett, T. (2003). Use of race and ethnicity in biomedical publication. Journal of the American Medical Association, 289(20), 2709-2716. https://doi.org/10.1001/ jama.289.20.2709

Kaufman, J. S., \& Cooper, R. S. (2001). Commentary: Considerations for use of racial/ ethnic classification in etiologic research. American Journal of Epidemiology, 154(4), 291-298. https://doi.org/10.1093/aje/154.4. 291

Khalfani, A. K., Zuberi, T., Bah, S., \& Lehohla, P. J. (2008). Race and population statistics in South African. In T. Zuber \& E. Bonilla-Silva (Eds.), White logic, white methods: Racism and methodology (pp. 63-90). Rowman \& Littlefield Publishers.

LaVeist, T. A. (1994). Beyond dummy variables and sample selection: What health services researchers ought to know about race as a variable. Health Services Research, 29(1), 1-16.

Lewis, J. E., Degusta, D., Meyer, M. R., Monge, J. M., Mann, A. E., \& Holloway, R. L. (2011). The mismeasure of science: Stephen Jay Gould versus Samuel George Morton on skulls and bias. PLoS Biology, 9(7), 1-6. https://doi.org/10.1371/annotation/ 138c7c99-249f-432c-a4f7-2993b7b87c0a

López, G. R., \& Warren, C. (2015). Critical race theory. Oxford Bibliographies in Education. https://doi.org/10.1093/obo/978019975 6810-0124

Magaña, S., Parish, S., Morales, M. A., Li, H., \& Fujiura, G. (2016). Racial and ethnic health disparities among people with intellectual and developmental disabilities. Intellectual and Developmental Disabilities, 54(3), 161-172. https://doi.org/10.1352/1934-9556-54.3.161

McCoy, D., Winkle-Wagner, R., \& Luedke, C. (2015). Colorblind mentoring? Exploring white faculty mentoring of students of color. Journal of Diversity in Higher Education, 8(4), 225-242. https://doi.org/10.1037/a0038676

Mitchell, P. W. (2018). The fault in his seeds: Lost notes to the case of bias in Samuel George Morton's cranial race science. PLOS Biology, 16(10), 1-16. https:/doi.org/10.1371/journal.pbio. 2007008

Moore, C. L., Feist-Price, S., \& Alston, R. J. (2002). VR services for persons with severe/profound mental retardation: Does race matter? Rehabilitation Counseling Bulletin, 45(3), 162-167. https://doi.org/10.1177/00343552020450 0305

Moore, C. L., Ferrin, J. M., Haysbert, N., Brown, S., Cooper, P., Diebel, J., Washington, A., Sassin, J., Manyibe, E., Azadian, M., \& Cantrell, C. (2009). Employment outcome rates of African American versus White consumers of vocational rehabilitation services: A meta-analysis. Journal of Applied Rehabilitation Counseling, 40(3), 3-10. https://doi. org/10.1891/0047-2220.40.3.3

Moore, P., \& Toliver, S. (2010). Intraracial dynamics of Black professors' and Black students' communication in traditionally White colleges and universities. Journal of Black Studies, 40(5), 932-945. https://doi. org/10.1177/0021934708321107

Nicolaidis, C., Raymaker, D., Kapp, S. K., Baggs, A., Ashkenazy, E., McDonald, K., Weiner, M., Maslak, J., Hunter, M., \& Joyce, A. (2019). The AASPIRE practice-based guidelines for the inclusion of autistic adults in research as co-researchers and study participants. Autism, 23(8), 2007-2019. https://doi.org/10.1177/ 1362361319830523 
Omi, M., \& Winant, H. (2015). Racial formation in the United States (3rd ed.). Routledge.

Rice, C., Harrison, E., \& Friedman, M. (2019).

Doing justice to intersectionality in research. Cultural Studies Critical Methodologies, 19(6), 409-420. https://doi.org/10.1177/ 1532708619829779

Siperstein, G., Heyman, M., \& Stokes, J. (2014). Pathways to employment: A national survey of adults with intellectual disabilities. Journal of Vocational Rebabilitation, 41(3), 165-178. https://doi:10.3233/JVR140711

Skiba, R. J., Simmons, A. B., Ritter, S., Gibb, A. C., Rausch, M. K., Cuadrado, J., \& Chung, C. G. (2008). Achieving equity in special education: History, status, and current challenges. Exceptional Children, 74(3), 264-288. https:// doi.org/10.1177/001440290807400301

Stancliffe, R. J., \& Lakin, K. C. (2006). Minority status, consumer outcomes, and service inputs in four states. Mental Retardation, 44(3), 165183. https://doi.org/10.1352/00476765(2006)44[165:mscoas $] 2.0 . c 0 ; 2$

Stewart, Q. T. (2008). Swimming upstream: Theory and methodology in race research. In T. Zuberi \& E. Bonilla-Silva (Eds.), White logic, white methods (pp. 111-126). Rowan \& Littlefield Publishers.

Tsagaris, G. S., Seck, M. M., Keeler, J., \& Rowe, R. (2016). Geographic information system analysis of developmentally disabled adult offenders. Journal of Intellectual Disabilities and Offending Behaviour, 7(1), 4-13. https://doi. org/10.1108/JIDOB-09-2015-0028

Wehman, P., Sima, A. P., Ketchum, J., West, M. D., Chan, F., \& Luecking, R. (2015). Predictors of successful transition from school to employment for youth with disabilities. Journal of Occupational Rehabilitation, 25(2), 323334. https://doi.org/10.1007/s10926-0149541-6

Williams, D. R., \& Mohammed, S. A. (2013a). Racism and health I: Pathways and scientific evidence. American Behavioral Scientist, 57(8), 1152-1173. https://doi.org/10.1177/ 0002764213487340

Williams, D. R., \& Mohammed, S. A. (2013b). Racism and health II: Needed research agenda for effective interventions. American Behavioral Scientist, 57(8), 1200-1226. https://doi.org/ $10.1177 / 0002764213487341$

Zuberi, T. (2001). Thicker than blood: How racial statistics lie. University of Minnesota Press.

Zuberi, T., \& Bonilla-Silva, E. (2008). White logic, white methods: Racism and methodology. Rowman \& Littlefield Publishers.

Zuberi, T., Patterson, E. J., \& Stewart, Q. T. (2015). Race, methodology, and social construction in the genomic era. The Annals of the American Academy of Political and Social Science, 661(1), 109-127. https://doi.org/10.1177/ 0002716215589718

Received 12/15/2020, accepted 4/13/2021.

We would like to extend our sincerest gratitude to Drs. Brian Boyd (University of Kansas) and Anne Kirby (University of Utah) for their thoughtful feedback in clarifying and expanding ideas presented in this article.

\section{Authors:}

Khalilah Robinson Johnson, University of North Carolina at Chapel Hill; Matthew Bogenschutz, Virginia Commonwealth University; and Kierra Peak, University of North Carolina at Chapel Hill.

Correspondence concerning this article should be addressed to Dr. Khalilah Robinson Johnson, University of North Carolina at Chapel Hill, Department of Allied Health Sciences, Bondurant Hall, Campus Box \#7122, Chapel Hill, North Carolina,27599-7120 (e-mail: Khalilah_Johnson@ med.unc.edu). 